\title{
The impact of phonological complexity on past tense inflection in children with Grammatical-SLI
}

\author{
CHLOE R. MARSHALL \& HEATHER K. J. VAN DER LELY
}

University College London, UK

\begin{abstract}
English-speaking children with Specific Language Impairment (SLI) variably produce inflected and bare stem forms in obligatory past tense contexts. Researchers have not reached consensus as to whether the underlying deficit is morphosyntactic or morphophonological in nature. The Computational Grammatical Complexity (CGC) Hypothesis takes a different tack: it hypothesizes that for children with a particular form of SLI, Grammatical-SLI, the deficit is in representing linguistic structural complexity in at least three components of the computational grammatical systemsyntax, morphology and phonology. Deficits in all these components are predicted to impact on regular past tense formation. The impact of syntactic and morphological complexity on G-SLI children's realization of tense has been tested previously. Here we complete the picture by considering phonological effects on their production of regular past tense inflection. Using a past tense elicitation task where we manipulate the phonological complexity of the inflected verb end, we show that, as predicted, verb-end phonological complexity impacts on suffixation: G-SLI children are less likely to suffix stems when the inflected form ends in a consonant cluster. Typically developing controls show no such effect. The results of this study highlight the need to consider the independent contributions of language components to impaired and normal performance.
\end{abstract}

Keywords: Grammatical-specific language impairment, past tense inflection, phonological complexity, computational grammatical complexity hypothesis, consonant clusters.

\section{Introduction}

Past tense morphology in SLI

Children with Specific Language Impairment (SLI) have significantly impaired language acquisition in the absence of any obvious language-independent cause, such as hearing loss, low non-verbal IQ, motor difficulties or neurological damage (see Leonard, 1998, for a review). Within the SLI population as a whole, deficits have been diagnosed in syntax, morphology, phonology and the lexicon (Leonard, 1998). The language deficit is not uniform, however: it is well-established that Englishspeaking children with SLI have difficulties in marking tense and agreement that extend above and beyond their overall language delay. This deficit manifests itself in the production of both inflected and bare stem forms in contexts that require the verb to be inflected (Loeb \& Leonard, 1991; Oetting \& Horohov, 1997; Rice, Wexler \& Cleave, 1995; Ullman \& Gopnik, 1999). Indeed, the omission of past tense $-e d$, third person singular $-s, b e$ and $d o$ is considered to be a clinical marker for SLI (Rice \& Wexler, 1996; Rice et al., 1995). Importantly, the omission of these morphemes in obligatory contexts is optional, but where they are supplied, they are generally supplied correctly. Although these findings have been replicated in many studies (Conti-Ramsden \& Windfuhr, 2002; Loeb \& Leonard, 1991; Norbury, Bishop \& Briscoe, 2001; Oetting \& Horohov, 1997; Ullman \& Gopnik, 1999; van der Lely \& Ullman, 2001), there is little consensus as to their underlying cause.

Several researchers see the deficit as being linguistic, and principally morphosyntactic, in nature (Clahsen, 1989; Clahsen, Bartke \& Gollner, 1997; Gopnik, 1999; Rice \& Wexler, 1996; Ullman \& Gopnik, 1999; van der Lely \& Ullman, 2001). For example, Rice and Wexler's Extended Optional Infinitive (EOI) Hypothesis and its more recent extension, the Unique Checking Constraint (UCC) Hypothesis (Rice \& Wexler, 1996; Rice et al., 1995; Rice, Wexler \& Hershberger, 1998; Rice, Wexler \& Redmond, 1999; Wexler, 1998), claim that syntactic features which mark tense and agreement inflection 
develop later than normal. SLI children experience a prolonged period in which they are not able to obligatorily mark tense and agreement; during this time, both inflected and uninflected stems are acceptable forms in their grammar. The term "extended" is used because an optional infinitive stage is also characteristic of younger, typically developing children. However, while typically developing children cease to use optional infinitives at about age 3, children with SLI still produce them for many years beyond that age.

The Computational Grammatical Complexity (CGC) Hypothesis hypothesizes that for children with a particular form of SLI, Grammatical-SLI, the deficit is in representing linguistic structural complexity in at least three components of the computational grammatical system - syntax, morphology and phonology (Marshall, 2004, 2006; van der Lely, 2005). Deficits in all these components are predicted to impact on regular past tense formation. We return to the CGC Hypothesis and its predictions for past tense marking in more detail in the next section.

The claims of a morphosyntactic deficit in SLI have been criticized by researchers who propose it is the phonological properties of regular past tense forms that place the suffix at risk of omission, not an impairment in a suffixation rule per se (Bernhardt $\&$ Stemberger, 1998; Joanisse \& Seidenberg, 1998, 2003; Leonard, 1989; McClelland \& Patterson, 2002). There is evidence that some SLI children have difficulty processing rapidly-presented sequential information, and this is hypothesized to affect the processing of acoustic stimuli (McClelland \& Patterson, 2002; Tallal \& Piercy, 1973a, b). This deficit is predicted to impact in particular on the acoustically non-salient $/ \mathrm{t} /$ and $/ \mathrm{d} /$ inflections, resulting in poor phonological representations of past tense forms. In Joanisse's (2004) model, he stresses the phonological similarity between the stem and past tense forms of regular verbs, e.g., walk and walked. He proposes that children with SLI have difficulties in translating the acoustic forms of words into a phonological code necessary for learning the past tense.

The Surface Hypothesis (Leonard, 1989, 1998) claims that SLI children have slow and limited processing abilities. These slow processing abilities are hypothesized to affect the realization of English inflection because it is frequently represented by suffixes that have low perceptual salience, e.g., past tense $/ \mathrm{t} /$ and $/ \mathrm{d} /$, plural and third person $/ \mathrm{s} /$ and $/ \mathrm{z} /$. For a cognitive system that is already under strain due to a deficit in processing ability, the lack of perceptual saliency of these morphemes makes them more difficult to process than would typically be the case. This in turn leads to difficulty in setting up morphological paradigms (in the sense of Pinker, 1984). Of critical importance to the Surface Hypothesis is the interaction between morphology and phonology. It is not that the perception of, say, word-final /t/ per se that is difficult for SLI children. Rather, it is because their limited processing ability is taxed when this sound plays a morphological role that there are repercussions for a word with a past tense inflection, such as missed. In this case they have to relate missed to miss, hypothesize that the $/ \mathrm{t} /$ is a morpheme in its own right and place it in the correct morphological paradigm. A monomorphemic word such as mist, in contrast, does not pose these difficulties.

Importantly, Joanisse (2004), Leonard (1998) and other researchers (Bernhardt and Stemberger, 1998; Joanisse \& Seidenberg, 1998; Tallal \& Piercy, 1973a, b), propose that inflectional deficits arise from difficulties with perception and slow processing that affect morphosyntax, rather than from a deficit in morphosyntax itself. However, given that a significant proportion of children with SLI do not have perceptual deficits (Bishop, Carlyon, Deeks, \& Bishop, 1999; van der Lely, Rosen, \& Adlard, 2004), should we expect all children with SLI to manifest the same type of past tense deficit?

\section{Subgroups of SLI and the G-SLI population}

Heterogeneity of language deficits within the SLI population has been acknowledged (see discussion in Bishop, 2003; Leonard, 1998; van der Lely, 2003), but is not accommodated within most current theories. Moreover, given the robust findings of past tense deficits in the SLI population, the significance of heterogeneity with regards to past tense inflection is not well understood.

The existence of subgroups of SLI children whose members share a common profile of linguistic strengths and weaknesses has been proposed, but is controversial (Aram, Morris \& Hall, 1993; Aram \& Nation, 1975; Rapin \& Allen, 1983). It is of course possible that what appear to be different subgroups are just variable manifestations of a common language disorder (Bishop, 1997). On the other hand, van der Lely and her colleagues have identified a subgroup of children that they classify as having Grammatical (G)-SLI. G-SLI children's language difficulties are claimed to be relatively homogeneous and to encompass the core aspects of grammarsyntax, morphology and phonology, whereas the lexicon, including derivational morphology, is relatively spared, and pragmatics and articulation are unaffected (Gallon, Harris, \& van der Lely, under revision; Marshall, Harris \& van der Lely, 2003; Marshall \& van der Lely, 2007; van der Lely, 1997a, b, 1998, 2005; van der Lely \& Battell, 2003; van der Lely, Rosen, \& McClelland, 1998; van der Lely \& Stollwerck, 1997).

Like other children with SLI, those with G-SLI have difficulty marking tense. Van der Lely and Ullman investigated regular and irregular past tense formation in a group of twelve children with G-SLI, aged $9 ; 03-12 ; 10$, and in three groups of typically 
developing children matched on standardized measures of morphology and vocabulary (van der Lely $\&$ Ullman, 2001). They found that the G-SLI and language-matched controls showed quantitatively and qualitatively different patterns of performance. The G-SLI children's production of regular past tense forms was significantly lower than that of all three control groups. Their performance on irregular past tense verbs was lower than that of the two groups matched for vocabulary level but not significantly different from the group matched for morphology. These findings suggested that the difficulties G-SLI children face with regular inflection could not be solely accounted for by their language age. Two patterns in the data were crucial to van der Lely and Ullman's interpretation of those data:

- the control children showed a significant advantage for regular over irregular verbs, whereas the G-SLI children did not;

- the G-SLI children showed a consistent frequency effect for both regular and irregular verbs, whereas the controls did so only for irregular verbs.

Van der Lely and Ullman claimed that G-SLI children preferentially retrieve stored regular forms from the lexicon, whereas typically developing children compose regular forms de novo from the verb stem and past tense morpheme. In other words, G-SLI children have a deficit creating morphologically complex forms, which results from them being inconsistent in their use of the regular suffixation rule, and having to rely instead on the storage of forms that are already inflected.

In a test of van der Lely and Ullman's hypothesis, Marshall and van der Lely compared G-SLI children's production of two types of regular verbs that differ in the phonotactics of the cluster formed at the inflected verb end (Marshall \& van der Lely, 2006). Monomorphemically legal verbs end in a cluster that is also found in monomorphemic (i.e., uninflected) words (e.g., missed/mist; rolled/gold), whereas monomorphemically illegal verbs end in a cluster that is not found in monomorphemic words (e.g., hugged, robbed, rushed). Marshall and van der Lely reasoned that if G-SLI children store past tense forms, then cluster frequency should affect inflectional accuracy (independently of verb frequency), and verbs ending in a legal cluster should be more readily inflected than those with an illegal cluster, as legal clusters are considerably more frequent than illegal clusters (this is because they occur in both monomorphemic and inflected forms, whereas illegal clusters occur only in inflected forms). This was indeed the case-a reanalysis of van der Lely and Ullman's data, and data from a new group of G-SLI children, showed that G-SLI children found it easier to inflect verbs that form legal rather than illegal clusters, whereas typically developing children showed no effect of phonotactics (Marshall \& van der Lely, 2006). Hence the data supported the hypothesis that G-SLI children store regular past tense forms. A further explanation is that G-SLI children create new past tense forms by analogy to forms that they have already stored, and that forms that contain legal clusters were produced more readily because legal clusters are more frequent. In either case, G-SLI children showed a qualitatively different pattern of performance compared to their language matched controls.

However, the past tense deficit is not solely a morphological deficit-it also has a syntactic component (van der Lely, 2005). G-SLI children inconsistently manipulate core aspects of syntax such as the assignment of thematic roles to noun phrases, the assignment of coreference to pronouns and anaphors when only syntactic cues are available, and the production of questions requiring Wh-movement (van der Lely, 2005). In order to explain this deficit in syntax, van der Lely claims that G-SLI children have difficulty in setting up syntactic dependencies that depend on "Movement" (Chomsky, 1995). The realization of tense and agreement features requires a syntactic dependency between the verb and the inflection node. If this dependency is not created, then tense and agreement features cannot be checked, and therefore not spelt out on the verb (Chomsky, 2000, 2001; Davies, 2001). This deficit in syntactic dependencies can account for the G-SLI group's poor performance on both regular and irregular verbs in the past tense task, and the deficit in producing morphologically complex forms can explain why the deficit is worse for regulars than irregulars relative to typically developing children. In other words, individuals with G-SLI have a dual deficit-in syntax and in morphology.

Those researchers who favour an auditory processing/phonological deficit underlying SLI (e.g., Bernhardt \& Stemberger, 1998; Joanisse \& Seidenberg, 2003) claim that van der Lely and Ullman's past tense data, and those of other researchers, can be explained as follows: it is the phonological properties of regular past tense forms that place the suffix at risk of omission, and not an impairment in a suffixation rule per se.

The problem with this view, at least for the G-SLI subgroup, is that G-SLI children have no consistent auditory deficit, and their performance on tasks involving auditory discrimination does not correlate with phonological and other language abilities. Even more troubling is the finding that several control children, who by definition have normal language skills, performed poorly on the auditory tasks (van der Lely et al., 2004). This indicates that auditory processing difficulties are neither necessary nor sufficient to cause G-SLI (Bishop et al., 1999). This of course does not rule out the possibility that G-SLI 
children had auditory processing deficits at some earlier stage of development, but that particular hypothesis can only be tested through longitudinal studies, which have yet to be carried out.

Meanwhile, recent work has shown that despite a lack of an observable auditory deficit, certain aspects of phonological structure do cause difficulty for children with G-SLI. Children with G-SLI have clear and fluent speech, and are intelligible for known words. Their phonological deficit manifests as a difficulty with forms that are complex at the syllable and foot levels of the prosodic hierarchy (Gallon et al., under revision; Marshall et al., 2003). In a nonword repetition task, G-SLI children simplify consonant clusters in word-initial, word-medial and word-final positions, while the presence of unfooted syllables causes syllabic simplifications and segmental changes elsewhere in the word (Marshall, 2004; Marshall, Ebbels, Harris, \& van der Lely, 2002).

Rather than treating the syntactic, morphological and phonological deficits as separate impairments, they are unified in a model that has been proposed to account for the full range of language deficits found in G-SLI children: the Computational Grammatical Complexity (CGC) Hypothesis (Marshall, 2004, 2006; van der Lely, 2005). We use the terms "computational" and "grammatical" because the core computational components of grammar (syntax, morphology and phonology) are affected, and "complexity" because the most parsimonious explanation is that the deficit in each component of grammar lies in the formation of complex structural representations. In particular, the construction of hierarchically organized structures-such as those required for syntactic dependencies that require movement (e.g., between a wh-word and its trace), for the creation of inflectionally suffixed forms, and for the construction of complex syllable structure-is problematic for these children (see van der Lely, 2005, for a more detailed exposition).

The CGC Hypothesis makes a prediction which we test in this paper-because phonological complexity is a feature of regular past tense formation in English, we would expect G-SLI children to find verbs with phonologically complex endings harder to inflect than verbs which are phonologically simple (van der Lely, 2005). In the next section we therefore discuss an aspect of phonological complexity that is involved in regular past tense forms-consonant clusters - and how this complexity impacts on past tense inflection in SLI.

\section{The phonology of past tense forms} and its effects in SLI

Irregular past tense forms tend not to contain clusters (e.g., took, swam, got, stood) but if they do (e.g., slept, built, spent, lost) then those clusters are from a restricted set, in that they have to also occur in monomorphemic words (cf. accept, stilt, tent, frost) and they can contain no more than two consonants. Some regularly inflected forms, however, contain clusters that either can or can not occur in monomorphemic English words (e.g., the cluster at the end of hugged has no monomorphemic equivalent). In addition, a few regularly inflected forms contain clusters with three consonants, e.g., danced and jumped, whereas irregular forms do not contain such large clusters.

Interactions between syllable structure and morphology in typical development have been studied by several authors. A child who is unable to produce word final consonants or clusters is not expected to produce them in morphologically complex words. In support of this prediction, Stemberger and Bernhardt (1997) reported a child who reduced clusters in both monomorphemic and suffixed words, e.g., the $/ \mathrm{ks} /$ in fox and rocks is reduced to $/ \mathrm{k} /$. However, the pattern was not always straightforward. Stemberger and Bernhardt reported a different child who produced word-final clusters only in suffixed forms. They also reported data from a child who reduced monomorphemic clusters differently to clusters in suffixed forms. Therefore, the way in which children treated complex structures in monomorphemic forms did not necessarily match how they treat them in suffixed forms. Song and Demuth (2005) revealed that frequency is an important factor in children's success with grammatical morphemes-both the input frequency of the grammatical morpheme itself (e.g., plural versus third person singular) and the frequency of the phonological structure in which that morpheme is encountered (single consonant versus consonant cluster). Kirk and Demuth (2005) showed that the segmental content of final clusters is a further factor in accurate realization: for example, in their study children acquired stop $+/ \mathrm{s} /$ clusters before $/ \mathrm{s} /+$ stop clusters.

It is unclear whether verb-end phonology affects inflectional morphology to a greater extent in SLI children compared to younger language-matched peers. One study showed that 6-year-old SLI children and their 4-year-old language-matched controls found past tense forms without a cluster easier to inflect than those with a cluster, but that forms with a cluster were not disproportionately more difficult for the SLI children (Oetting \& Horohov, 1997). Another study similarly showed that word-end phonology affects both SLI children (aged $3 ; 7$ to $5 ; 9$ ) and their language-matched controls (aged 2;5 to 3;3) (Bortolini \& Leonard, 2000). The two groups showed a correlation between final cluster reduction in monomorphemic words and the omission of consonantal inflections (not only past tense, but also plural, genitive and third person $-s$ ), but the SLI group produced considerably more final cluster reduction on monomorphemic words than their controls. However, this study did not directly compare inflection rates where the past tense form has a cluster and forms where it does not. 
A third study revealed that phonological complexity of the verb stem, as indexed by the presence of a cluster at the onset, a cluster at the end, or by clusters at both the beginning and the end, had an effect on past tense inflectional accuracy in both children with SLI aged 7;2-13;0 and their language matched controls (Norbury et al., 2001).

As for the G-SLI group, van der Lely and Ullman's (2001) study did not investigate the impact of phonology. However, in a case study of one particular G-SLI boy, AZ, van der Lely (1997b) noted that the only verbs for which $\mathrm{AZ}$ produced inflection in van der Lely and Ullman's elicitation task were mar and stir; those past tense forms, marred and stirred, which do not end in a cluster in this child's dialect of English.

What is clear is that the relationship between phonology and morphology merits being studied in a systematic way. One approach would be to choose verb stimuli that differ according to verb-end complexity, and investigate whether SLI children are disproportionately affected compared to their controls, i.e., whether there is an interaction between group and complexity. This is the method that we use in the study reported here, with a group of children with G-SLI.

\section{Method \\ Participants}

Three groups of children participated in this experiment-one group of G-SLI children and two groups of typically developing children. 14 G-SLI participants (age range 9;09-16;03, mean age 12;03) were selected on the basis of a persistent deficit in grammatical production and comprehension, as revealed by both standardized language tests and tests designed specifically to target the difficulty with complex syntactic structures that characterizes this group. The precise selection criteria for the G-SLI subgroup are well-documented but for ease of reference we will discuss them briefly here (van der Lely, 1997a, b, 1998; van der Lely et al., 1998; van der Lely \& Stollwerck, 1997). Note that this group of children are not the same as those who participated in the studies listed above, but are the same as those who participated in Marshall's (2004) and Marshall and van der Lely's (2006) studies. They all had a diagnosis of SLI from a qualified speech and language therapist, fell below 1.5 standard deviation on at least two standardized tests of language, and were receiving speech and language therapy either in special language schools or in language units in mainstream schools. They were aged 9;00 years and over, and had non-verbal IQs in the normal range (i.e., 85 and above, as measured by the Raven's Progressive Matrices (Raven, 1998) and/or the block design subtest of the British Ability Scales (Elliott, 1996)). Articulation of known words (i.e., words established in the child's vocabulary) was clear and consistent, by speech and language therapist report.

To be included in the G-SLI group, the children had to be significantly impaired in aspects of grammar that are thought to be core to the computational grammatical system. Specifically, they had to evince more than $20 \%$ errors on an expressive test of subject-verb agreement and tense marking (the Verb Agreement and Tense Test, van der Lely, 2000), a test of assigning thematic roles in reversible sentences (the Test of Active and Passive Sentences, van der Lely, 1996) and a test of assigning reference to pronouns and reflexives (the Advanced Syntactic Test of Pronominal Reference, van der Lely, 1997c). See Appendix 1 for details of individual participants.

Twenty-eight typically developing children also participated; 14 were matched on raw score $( \pm 1)$ to individual G-SLI children on a test of sentence comprehension, the Test for Reception of Grammar (Bishop, 1993), and 14 were individually matched on raw score $( \pm 3)$ on the British Picture Vocabulary Scales (Dunn, Dunn, Whetton, \& Burley, 1997). They were then divided into two groups according to age, in order to give a picture of typical development. The Typically Developing 1 (TD1) control group were aged 4;06-7;05, with a mean age of $6 ; 00$, and the Typically Developing 2 (TD2) control group were aged $7 ; 06-12 ; 00$, with a mean age of $9 ; 06$. See Table I for details of the participant groups. The dialect of all participants was Standard British English.

\section{Verb stimuli}

Three conditions of verbs were selected, which varied according to the complexity of their past tense form. The characteristics of each condition with regards to verb-end complexity are presented in Table II, and the full list of verbs can be found in Appendix 2.

We matched verbs on the basis of two frequency counts: the British English COBUILD corpus of the University of Birmingham, by the Centre for Lexical Information (CELEX) at the University of Nijmegen

Table I. Participant details.

\begin{tabular}{|c|c|c|c|c|c|}
\hline \multicolumn{3}{|l|}{ Measure } & \multirow{2}{*}{$\begin{array}{c}\begin{array}{c}\text { G-SLI } \\
(\mathrm{N}=14)\end{array} \\
12 ; 03 \\
(1 ; 11)\end{array}$} & \multirow{2}{*}{$\begin{array}{c}\text { TD1 } \\
\text { controls } \\
(\mathrm{N}=14)\end{array}$} & \multirow{2}{*}{$\begin{array}{c}\begin{array}{c}\mathrm{TD} 2 \\
\text { controls } \\
(\mathrm{N}=14) \\
9 ; 06 \\
(1 ; 02)\end{array}\end{array}$} \\
\hline Age & & $\begin{array}{l}\text { Mean } \\
\text { (SD) }\end{array}$ & & & \\
\hline TROG & Raw score & $\begin{array}{l}\text { Mean } \\
\text { (SD) }\end{array}$ & $\begin{array}{l}12.86 \\
(3.51)\end{array}$ & $\begin{array}{l}10.79 \\
(2.78)\end{array}$ & $\begin{array}{l}16.43 \\
(1.87)\end{array}$ \\
\hline & z-score & $\begin{array}{l}\text { Mean } \\
\text { (SD) }\end{array}$ & $\begin{array}{l}-1.67 \\
(.61)\end{array}$ & $\begin{array}{l}-.14 \\
(.63)\end{array}$ & $\begin{array}{l}.12 \\
(.89)\end{array}$ \\
\hline \multirow[t]{2}{*}{ BPVS } & Raw score & $\begin{array}{l}\text { Mean } \\
\text { (SD) }\end{array}$ & $\begin{array}{c}79.93 \\
(20.11)\end{array}$ & $\begin{array}{c}60.00 \\
(12.90)\end{array}$ & $\begin{array}{c}94.12 \\
(12.80)\end{array}$ \\
\hline & z-score & $\begin{array}{l}\text { Mean } \\
\text { (SD) }\end{array}$ & $\begin{array}{c}-1.54 \\
(.76)\end{array}$ & $\begin{array}{l}.28 \\
(.63)\end{array}$ & $\begin{array}{l}.28 \\
(.50)\end{array}$ \\
\hline
\end{tabular}

Note: TROG: Test for Reception of Grammar. BPVS: British Picture Vocabulary Scales. 
Table II. Phonological and mean frequency characteristics of each condition.

\begin{tabular}{|c|c|c|c|c|c|c|}
\hline \multirow[b]{2}{*}{ Condition ${ }^{\star}$} & \multirow[b]{2}{*}{ Consonants at verb end } & \multirow[b]{2}{*}{ Example } & \multicolumn{2}{|c|}{ COBUILD frequency } & \multicolumn{2}{|c|}{ CHILDES frequency } \\
\hline & & & Lemma Mean (SD) & Past Mean (SD) & Lemma Mean (SD) & Past Mean (SD) \\
\hline $\mathrm{V}-\mathrm{D}(\mathrm{N}=8)$ & 1 & paid & $5.76(1.53)$ & $3.99(1.68)$ & $4.53(2.08)$ & $2.34(1.73)$ \\
\hline VC-D $(\mathrm{N}=16)$ & 2 & hugged & $5.44(.90)$ & $3.76(1.00)$ & $4.70(.92)$ & $2.81(.80)$ \\
\hline VCC-D $(\mathrm{N}=8)$ & 3 & danced & $4.86(.93)$ & $2.97(.88)$ & $4.25(2.04)$ & $1.68(1.27)$ \\
\hline
\end{tabular}

*The reader will note that there are twice as many items in the VC-D condition as in the V-D and VCC-D conditions. This is because in an earlier experiment, Marshall and van der Lely (2006) compared performance on two different types of VC-D verbs-those ending in a phonotactically legal cluster, e.g., yelled, and those ending in a phonotactically illegal cluster, e.g., hugged.

(Baayen, Piepenbrock \& van Rijn, 1993), and the Parental Frequency count from the CHILDES database (MacWhinney, 2000). The former is calculated principally from written sources and contains 17.9 million tokens. The Parental Frequency count from CHILDES comes from childdirected speech or speech heard by children and contains 2.6 million tokens. The latter might seem a better measure of children's familiarity with individual verbs. However, van der Lely and Ullman (2001) carried out a stem familiarity task which showed a very high and significant correlation between the COBUILD frequency counts and children's familiarity ratings, indicating that the COBUILD frequencies are indeed an appropriate estimate for these children.

Individual verb frequencies were augmented by 1 and $\ln$-transformed. For the COBUILD frequency count, one way ANOVAS showed no significant differences between conditions for either lemma frequency, $\mathrm{F}(2,31)=1.421, \mathrm{p}=.258$, or past tense frequency, $\mathrm{F}(2,31)=1.735, \mathrm{p}=.194$. For the CHILDES parental frequency count, one-way ANOVAs likewise revealed no significant differences between conditions for either lemma frequency, $\mathrm{F}(2,31)=.217, \mathrm{p}=.806$, or past tense frequency, $\mathrm{F}(2,31)=2.389, \mathrm{p}=.110$.

\section{Procedure}

The procedure was that used by Marshall and van der Lely (2006), and based on van der Lely and Ullman (2001). The lead in for the task presented both the past tense and bare stem form. Last week Kipper robbed a post office. Everyday I rob a post office. Yesterday $I . . . . \ldots$. Hence the lead in primed the syntactic form of the past tense, as did the inclusion of only regular stimuli. A further modification to van der Lely and Ullman's task was that none of our verb stimuli had onset clusters, so that phonological complexity occurred only at the verb end. Finally, all verbs were followed by a vowelinitial word in the stimulus sentence, because wordfinal $/ \mathrm{t} /$ and $/ \mathrm{d} /$ are more likely to be deleted in normal speech when the next word begins with a consonant (Guy, 1991). We reasoned that constructing stimulus sentences so that each verb was followed by a vowel-initial word would reduce the likelihood of /t/ and /d/ being deleted for phonological rather than morphological reasons.

The experimenter introduced the child to two toy dogs. One of the dogs, Kipper, was likely to be familiar to the child through the popular children's books and television programmes. The experimenter reminded/told the child that Kipper is a very adventurous dog who does all sorts of exciting things. The second dog, who the child didn't know, was called Bean Dog. The experimenter told the child that Bean Dog is one of Kipper's best friends, but that he gets very jealous of Kipper and all the adventures that Kipper has. The experimenter explained that Kipper had been busy doing lots of things recently. Bean Dog was jealous and wanted to tell everyone that he had been doing them too. The experimenter asked the child to help her to be the voice of Bean Dog and tell everyone the things that he had been doing. There were four practice items using irregular verbs, which children were given feedback on, and 32 stimulus sentences, listed in Appendix 3. One pseudo-randomized list was created for all participants. Responses were recorded onto a Sony Digital Audio Tape-recorder TCD-D8 using an Audio-Technica microphone ATR20. Responses were transcribed live by the experimenter (first author) and subsequently checked from the audio-tape.

\section{Coding of responses}

Responses were coded as follows:

- Correct

- Bare stem

- Stem-final consonant deletion

- Other responses

$$
\begin{aligned}
& \text { e.g., hop } \rightarrow \text { hopped } \\
& \text { e.g., rob } \rightarrow \text { rob } \\
& \text { e.g., milk } \rightarrow \text { milt } \\
& \text { e.g., wash } \rightarrow \text { washing; } \\
& \text { judge } \rightarrow \text { jumped }
\end{aligned}
$$

\section{Predictions}

We hypothesized that G-SLI children would find the phonological complexity of the inflected verb-end, as realized by the presence versus absence of a cluster, and the size of the cluster, problematic. We predicted that this feature of regular past tense forms would cause more difficulty for the G-SLI group than for groups of typically developing, language-matched 
peers. More specifically, we considered cluster complexity by comparing performance on verbs with no cluster at the inflected verb end (e.g., sewed) versus those with a two-consonant cluster (e.g., wrapped) and three-consonant cluster (e.g., danced). The effects of phonological complexity might therefore partially explain why G-SLI children do not show the same advantage for regular over irregular verbs that typically developing children show. The majority of errors for all three groups were predicted to be bare stem forms (van der Lely \& Ullman, 2001).

\section{Results}

Data from one participant in the TD1 group (who happened to be the youngest child) were discarded for two reasons. Firstly, her answers were at times muffled and therefore difficult to transcribe accurately. Secondly, assuming that her answers had been scored correctly, she achieved a score of $34.38 \%$, which was 2.89 standard deviation below the mean for her group. Therefore these data represented an outlier performance of the TD1 group.

\section{Analysis of correct responses}

Correct responses to the elicitation task are shown in Table III. We carried out correlations for each group's correct performance against our lemma and past tense frequency measures. Not one correlation approached significance (Pearson values ranged between -.260 and .239 , and $\mathrm{p}$ values between .150 and .840), and therefore we do not use frequency as a covariate in the analysis that follows.

We investigated the effect of phonological complexity by comparing verbs with no clusters, twoconsonant clusters and three-consonant clusters at the inflected verb-end. Correct responses were analysed using a 3 (Group: G-SLI, TD1, TD2) x 3 (Condition: V-D, VC-D, VCC-D) ANOVA, and we applied Greenhouse-Geisser corrections because the data violated the assumption of sphericity. The analysis revealed significant main effects of complexity, $\mathrm{F}(1.466,76)=5.498, \mathrm{p}=.013$, and group, $\mathrm{F}(2$, $38)=7.450, \mathrm{p}=.002$, and a significant interaction

Table III. Correct responses for the elicitation task ${ }^{\star}$.

\begin{tabular}{llccc}
\hline Condition & & $\begin{array}{c}\text { G-SLI } \\
\text { (N=14) }\end{array}$ & $\begin{array}{c}\text { TD1 } \\
\text { controls } \\
(\mathrm{N}=13)\end{array}$ & $\begin{array}{c}\text { TD2 } \\
\text { controls } \\
(\mathrm{N}=14)\end{array}$ \\
\hline V-D & Mean (SD) & $6.64(1.65)$ & $7.31(.86)$ & $7.71(.61)$ \\
VC-D & Mean (SD) & $5.75(2.43)$ & $7.62(.71)$ & $7.79(.54)$ \\
VCC-D & Mean (SD) & $5.07(3.03)$ & $7.15(.90)$ & $7.64(.46)$ \\
All conditions & Mean (SD) & $5.82(2.37)$ & $7.36(.82)$ & $7.71(.54)$ \\
\hline
\end{tabular}

$\star$ For each cell, correct responses are out of a possible total of 8 , with VC-D out of 16 but divided by 2 to be comparable to other cells. between condition and group, $\mathrm{F}(2.931,76)=3.860$, $\mathrm{p}=.015$.

The condition $\mathrm{x}$ group interaction was investigated with a series of pairwise comparisons between conditions within each participant group. For the G-SLI group, performance was significantly better for the V-D compared to the VC-D condition, $\mathrm{t}(13)=2.253, \mathrm{p}=.042$, for the V-D compared to the VCC-D condition, $t(13)=2.797, p=.015$, and for the VC-D compared to the VCC-D condition, $\mathrm{t}(13)=2.267, \mathrm{p}=.041$. For the TD1 and TD2 groups, none of the pairwise comparisons reached significance, ( $\mathrm{t}$ between .322 and 1.720 , and $\mathrm{p}$ between .111 and .752). The pattern of correct performance with respect to verb-end complexity was therefore V-D > VC-D > VCC-D for the G-SLI group, but $\mathrm{V}-\mathrm{D}=\mathrm{VC}-\mathrm{D}=\mathrm{VCC}-\mathrm{D}$ for the controls.

The condition $\mathrm{x}$ group interaction was further investigated using a series of one-way ANOVAs within each condition, in order to identify group differences. For the V-D condition the effect of group was marginally significant, $F(2,40)=3.184$, $\mathrm{p}=.053$. For the VC-D condition the effect of group was significant, $\mathrm{F}(2,40)=7.745, \mathrm{p}=.002$. Post-hoc testing, applying the Games-Howell correction for multiple comparisons where variances are unequal, revealed that within the VC-D condition, the G-SLI group performed worse than the TD1 controls, $\mathrm{p}=.037$ and the TD2 controls, $\mathrm{p}=.021$, but the two control groups performed equivalently, $\mathrm{p}=.769$. For the VCC-D condition the effect of group was likewise significant, $\mathrm{F}(2,40)=7.371, \mathrm{p}=.002$. This time the G-SLI group did not perform significantly worse the LA1 controls, $\mathrm{p}=.064$, but did so compared to the LA2 controls, $\mathrm{p}=.019$. Once again, the control groups did not perform differently from one another, $\mathrm{p}=.258$.

Finally, we carried out correlations between correct score and complexity for each group, partialling out lemma and past tense frequencies. For the G-SLI group there was a significant negative correlation between score and complexity, $\mathrm{R}=-.4782, \mathrm{p}=.008$, whereas the correlations were not significant for the TD1 and TD2 groups, $\mathrm{R}=-.1263, \mathrm{p}=.506$, and $\mathrm{R}=-.0876, \mathrm{p}=.645$ respectively. These results confirm that the G-SLI children's inflectional accuracy was affected by increased complexity at the verb end, whereas that of the control groups was not.

\section{Error analysis}

Table IV shows the proportion of errors for each group and for each condition.

The most common error for all groups, as predicted, was the bare stem error. Deletion of a stem-final consonant was rare, and confined to VCC-D clusters. The examples were: solved $\rightarrow$ $\star /$ soldl, milked $\rightarrow \star /$ milt/, banged $\rightarrow \star /$ bænd/. The G-SLI group made this error only 4 times (four 
Table IV. Error responses ${ }^{\star}$.

\begin{tabular}{|c|c|c|c|c|c|}
\hline & Condition & & $\begin{array}{c}\text { G-SLI } \\
(\mathrm{N}=14)\end{array}$ & $\begin{array}{l}\text { TD1 controls } \\
(\mathrm{N}=13)\end{array}$ & $\begin{array}{l}\text { TD2 controls } \\
(\mathrm{N}=14)\end{array}$ \\
\hline \multirow{3}{*}{ Bare stem } & V-D & Mean (SD) & $.71(1.27)$ & $.54(1.04)$ & $.21(.58)$ \\
\hline & VC-D & Mean (SD) & $1.75(2.06)$ & $.35(.75)$ & $.21(.55)$ \\
\hline & VCC-D & Mean (SD) & $2.21(2.42)$ & $.62(.77)$ & $.36(.63)$ \\
\hline \multirow{3}{*}{$\begin{array}{l}\text { Stem-final } \\
\text { C-deletion }\end{array}$} & V-D & Mean (SD) & $\mathrm{n} / \mathrm{a}$ & $\mathrm{n} / \mathrm{a}$ & $\mathrm{n} / \mathrm{a}$ \\
\hline & VC-D & Mean (SD) & .00 & .00 & .00 \\
\hline & VCC-D & Mean (SD) & $.29(.47)$ & $.15(.38)$ & .00 \\
\hline \multirow[t]{3}{*}{ Other } & V-D & Mean (SD) & $.64(1.15)$ & $.15(.55)$ & $.07(.27)$ \\
\hline & VC-D & Mean (SD) & $.50(1.01)$ & $.04(.14)$ & .00 \\
\hline & VCC-D & Mean (SD) & $.43(1.09)$ & $.08(.28)$ & $.07(.27)$ \\
\hline
\end{tabular}

${ }^{\star}$ For each cell, correct responses are out of a possible total of 8 , with VC-D out of 16 but divided by 2 to be comparable to other cells.

different children), the TD1 controls only twice (two different children), and the TD2 controls not once.

In the "other" category, one child in the G-SLI group, OD, made 11 responses with -ing (omitting the auxiliary), e.g., *Yesterday I laughing instead of Yesterday I laughed. This type of error was not made by any of the control children. The remaining errors made by the G-SLI and LA1 groups were phonological changes to the stem, e.g., *waved for weighed, ${ }^{\star}$ saved for solved and *sign for sighed. The only error amongst the LA2 controls was an irregularization, whereby $\star / s u: /$ was produced in lieu of sewed.

It is difficult to argue that OD produces errors such as ${ }^{\star}$ Yesterday I laughing in order to avoid the clusters that would result from inflection. We therefore carried out two further analyses to test our finding that phonological complexity does indeed impact on the accuracy of inflection. First, when we removed OD's data from the analysis of correct scores, the effects of complexity, group and the interaction between complexity and group remained essentially unchanged. Secondly, an analysis of bare stem errors, using a 3 (Group: G-SLI, TD 1, TD2) $\times$ 3 (Condition: V-D, VC-D, VCC-D) ANOVA, replicated our analysis on correct scores. Once again, we found significant effects of complexity and group, $\mathrm{F}(1.492,76)=5.584, \mathrm{p}=.011$ and $\mathrm{F}(2,38)=$ $5.770, \mathrm{p}=.006$ respectively, and a significant interaction between complexity and group, F (2.984, $76)=4.223, \mathrm{p}=.009$

\section{Discussion}

In this study we set out to test the hypothesis that increasing the phonological complexity of the inflected verb end reduces the rate of successful past tense inflection for G-SLI children, but not for typically developing language-matched controls. The results support van der Lely and Ullman's finding that G-SLI children perform worse than younger, language-matched control children on tasks eliciting regular past tense forms (van der Lely \& Ullman, 2001). The majority of errors for all groups, as expected, were bare stem errors. The results go further than that original study and also reveal that the phonological complexity of the verb-end affects the ability of children with G-SLI group to use the past tense suffix, over and above their deficits in morphosyntax. G-SLI children are less likely to inflect a verb when the inflected verb end would contain a cluster. Phonological complexity does not affect inflection in typically developing children (matched on other aspects of grammar and vocabulary) of the ages tested here, although it may well have done so at an earlier age (Bernhardt \& Stemberger, 1998; Song \& Demuth, 2005; Stemberger \& Bernhardt, 1997).

The effect of phonological complexity on past tense inflection was predicted given findings that G-SLI children have difficulty repeating non-words containing consonant clusters (Gallon et al., under revision; Marshall et al., 2003). Compared to irregular verbs, regulars are more likely to have verb-end clusters, and so phonological complexity could be part of the explanation for the disproportionate difficulty that G-SLI children have with regular as opposed to irregular past tense morphology.

An alternative explanation for our results is that a processing or perceptual deficit caused the pattern of performance that we witnessed in the G-SLI group. Those accounts claim that deficits in processing the sorts of rapid temporal information that characterize the consonants $/ \mathrm{t} /$ and $/ \mathrm{d} /$ lead to a deficit in setting up the phonological representations for past tense, and hence to the suffix being omitted in production (Joanisse \& Seidenberg, 1998, 2003; Leonard, 1998; McClelland \& Patterson, 2002). However, there are several facts that militate such an account. Only a minority of children with G-SLI have an auditory deficit and there is no relationship between the magnitude of any auditory deficit and phonological, morphological and syntactic abilities. Indeed, many studies of SLI show that even the majority of SLI children in any one particular study do not have an auditory deficit (for a review, see Rosen, 2003). So although there is no doubt that auditory deficits and language impairments are co-morbid in some SLI children, there is no consistent causal relationship 
between the one and the other. Nor can an articulatory deficit explain our results, because children are not included in the G-SLI subgroup if they have verbal dyspraxia. Once again, research in the SLI population as a whole shows no causal relationship between speech and language impairments; rather, there appears to be little overlap between children with speech impairments and those with language impairments (Shriberg, Tomblin, \& McSweeny, 1999).

While phonology clearly plays a significant role in determining how successfully G-SLI children inflect verbs, locating the past tense deficit solely in the phonological aspects of language is too simplistic. A wealth of studies show that children with G-SLI have a range of syntactic and morphological deficits that cannot be accounted for solely by a phonological deficit (Marshall \& van der Lely, 2006; van der Lely, 2003; van der Lely \& Battell, 2003; van der Lely \& Christian, 2000; van der Lely \& Stollwerck, 1996, 1997). Instead, we propose that our data support the Computational Grammatical Complexity (CGC) Hypothesis, a model whereby independent deficits in syntax, morphology and phonology impact on regular past tense inflection. The production of regular past tense forms in English requires the production of complex syntactic, morphological and phonological structures, and children with G-SLI are impaired in producing exactly those types of structures. The CGC Hypothesis provides the most parsimonious explanation, not only for the past tense deficit, but for the full range of linguistic deficits seen in G-SLI.

Hypotheses which locate the deficit solely in the morphosyntax, e.g., the EOI/UCC Hypotheses (Rice \& Wexler, 1996; Wexler, 1998), would not be able to account for the effects of phonological complexity that we have found, because the EOI/UCC Hypotheses do not predict any impact of phonology on past tense inflection. The EOI/UCC Hypotheses could provide an explanation for the morphosyntactic impairment in SLI children, and they might hold, of course, for certain groups of SLI children, but they cannot fully account for the performance of children who have a concomitant phonological deficit, such as those with G-SLI. It is likely that different explanations are required for different types of SLI. It is therefore important for the reader to note that we are making our claims for a set of children with welldefined characteristics - it remains an empirical issue as to whether our results will hold for other types of SLI. However, our work raises the possibility that the reason past tense inflection is such a good marker for English-speaking SLI children is that it involves complexity in syntax, morphology and phonology. Furthermore, the CGC Hypothesis predicts that the linguistic structures that are difficult for G-SLI children cross-linguistically will depend on the degree of syntactic, morphological and phonological complexity in the particular language under investigation.
We would like to propose that the CGC Hypothesis has at least one particular theoretical advantage over hypotheses that advocate a single deficit in SLI. Its approach to studying SLI involves disentangling how deficits in different components of language impact on a particular linguistic form, such as tense. Recent genetic findings inform us that SLI is not a unitary phenomenon. It is becoming clear that there is no single genetic 'cause' of SLI, and that genetic investigations require theoretically motivated measures of underlying cognitive abilities (Bishop, 2006). One locus on Chromosome 16 has been linked to performance on non-word repetition task, which is a phonological task, whereas a locus on Chromosome 19 has been linked to expressive language tasks that require syntax (SLI Consortium, 2002). Similarly, a behavioural genetics study by Bishop, Adams and Norbury (2006) implicated different genes appear in phonological short-term memory and verb inflection deficits in SLI. There is increasing recognition that when investigating the genetics of language, attention should be focused on the different components of language (e.g., Kovas et al., 2005) and on specifying the phenotype as precisely as possible (Fisher, 2005). Phenotypic investigations must go beyond the "tense is a marker for SLI in English" variety, by investigating which components of language are involved in linguistic phenomena such as tense marking and determining how these break down. Even though the relationship between genotypes and phenotypes is likely to be complex (Fisher, 2005), we need detailed phenotypic data to both drive the genotypic studies and interpret their results. Such investigations will serve to further our understanding of the nature of language, and ultimately our understanding of how specialized cognitive systems develop.

\section{Acknowledgements}

We would like to thank the teachers and children at the following schools for helping us with our research: Moor House School, Hurst Green; Whitefield School, London; Middleton School, Leeds; Brockham Primary School, Dorking; Ifield Infant and Middle Schools, Crawley, and Southgate Infant School, Crawley. This work and the authors were supported by an ESRC studentship (R4220013421) awarded to Chloe Marshall and Wellcome Trust Grants (044179, 059876 and 063713) awarded to Heather van der Lely.

\section{References}

Aram, D., Morris, R., \& Hall, N. (1993). Clinical and research congruence in identifying children with specific language impairment. Fournal of Speech and Hearing Research, 36, 580591.

Aram, D., \& Nation, J. (1975). Patterns of language behaviour in children with developmental language disorders. Fournal of Speech and Hearing Research, 18, 229-241. 
Baayen, H., Piepenbrock, R., \& van Rijn, H. (1993). The CELEX Lexical Database, CD-ROM. Pennyslvania: Linguistic Data Consortium, University of Pennsylvania.

Bernhardt, B. H., \& Stemberger, J. P. (1998). Handbook of phonological development. London: Academic Press.

Bishop, D. (1983). Test for Reception of Grammar. Published by the author and available from the Age and Cognitive Performance Research Centre, University of Manchester.

Bishop, D. (1997). Is specific language impairment a valid diagnostic category? In J. Rispens, T. van Yperen, \& W. Yule (Eds.), Perspectives on the classification of specific developmental disorders (pp. 139-153). Dordrecht: Kluwer.

Bishop, D. (2003). Specific language impairment: Diagnostic dilemmas. In L. Verhoeven, \& H. van Ballzom (Eds.), Classification of developmental language disorders. Mahwah, NJ: Lawrence Erlbaum Associates.

Bishop, D. (2006). What causes specific language impairment in children? Current Directions in Psychological Science, 15, 217 221.

Bishop, D., Adams, C., \& Norbury, C. F. (2006). Distinct genetic influences on grammar and phonological short-term memory deficits: evidence from 6-year-old twins. Genes, Brain and Behaviour, 5, 158-169.

Bishop, D., Carlyon, R., Deeks, J., \& Bishop, S. (1999). Auditory temporal processing impairment: Neither necessary nor sufficient for causing language impairment in children. Fournal of Speech, Language, and Hearing Research, 42, 1295-1310.

Bortolini, U., \& Leonard, L. B. (2000). Phonology and children with specific language impairment: Status of structural constraints in two languages. Fournal of Communication Disorders, $33,131-150$.

Chomsky, N. (1995). The minimalist program. Cambridge, MA: MIT Press.

Chomsky, N. (2000). Minimalist inquiries: The framework. In R. Martin, D. Michaels, \& J. Uriagereka (Eds.), Step by step: Essays in honour of Howard Lasnik (pp. 89-155). Cambridge, MA: MIT Press.

Chomsky, N. (2001). Derivation by phase. In M. Kenstowicz (Ed.), Ken Hale: A life in language (pp. 1-52). Cambridge, MA: MIT Press.

Clahsen, H. (1989). The grammatical characterization of developmental dysphasia. Linguistics, 27, 897-920.

Clahsen, H., Bartke, S., \& Gollner, S. (1997). Formal features in impaired grammars: A comparison of English and German SLI children. Fournal of Neurolinguistics, 10, 151-171.

Conti-Ramsden, G., \& Windfuhr, K. (2002). Productivity with word order and morphology: A comparative look at children with SLI and children with normal abilities. International fournal of Language and Communication Disorders, 37, 17-30.

Davies, L. (2001). The nature of SLI: Optional and principle conflict. Unpublished doctoral thesis, University of London.

Dunn, L. M., Dunn, L. M., Whetton, C., \& Burley, J. (1997). British Picture Vocabulary Scales (second edition). Windsor: NFER Nelson.

Elliott, C. D. (1996). British Ability Scale (second edition). Windsor: NFER Nelson.

Fisher, S. (2005). Dissection of molecular mechanisms underlying speech and language disorders. Applied Psycholinguistics, 26, $111-128$.

Gallon, N., Harris, J., \& van der Lely, H. K. J. (in press). Non-word repetition: an investigation of phonological complexity in children with Grammatical-SLI. Clinical Linguistics and Phonetics.

Gopnik, M. (1999). Familial language impairment: More English evidence. Folia Phoniatrica et Logopaedica, 51, 5-19.

Guy, G. R. (1991). Explanation in variable phonology: An exponential model of morphological constraints. Language Variation and Change, 3, 1-22.

Joanisse, M. (2004). Specific Language Impairments in children: Phonology, semantics and the English past tense. Current Directions in Psychological Science, 13, 156-160.
Joanisse, M., \& Seidenberg, M. (1998). Specific Language Impairment: A deficit in grammar or processing? Trends in Cognitive Sciences, 2, 240-247.

Joanisse, M., \& Seidenberg, M. (2003). Phonology and syntax in specific language impairment: Evidence from a connectionist model. Brain and Language, 86, 40-56.

Kirk, C., \& Demuth, K. (2005). Asymmetries in the acquisition of word-initial and word-final consonant clusters. Fournal of Child Language, 32, 709-734.

Kovas Y., Hayiou-Thomas M., Oliver B., Dale P., Bishop D., \& Plomin R. (2005). Genetic and environmental origins of diverse language skills in $4 \frac{1}{2}$-year-old twin boys and girls. Child Development, 76, 632-651.

Leonard, L. B. (1989). Language learnability and specific language impairment in children. Applied Psycholinguistics, 10, $179-202$.

Leonard, L. B. (1998). Children with Specific Language Impairment. Cambridge, MA: MIT Press.

Loeb, D., \& Leonard, L. B. (1991). Subject case marking and verb morphology in normally developing and specifically language impaired children. Fournal of Speech and Hearing Research, 34, $340-346$

MacWhinney, B. (2000). The CHILDES Project (third edition). Mahwah, NJ: Lawrence Erlbaum.

Marshall, C. R., Ebbels, S., Harris, J., \& van der Lely, H. K. J. (2002). Investigating the impact of prosodic complexity on the speech of children with specific language impairment. UCL Working Papers in Linguistics, 14, 43-66.

Marshall, C. R., Harris, J., \& van der Lely, H. K. J. (2003). The nature of phonological representations in children with grammatical-specific language impairment. In D. Hall, T. Markopoulos, A. Salamoura, \& S. Skoufaki (Eds.), Proceedings of the University of Cambridge First Postgraduate Conference in Language Research (pp. 511-517). Cambridge: Cambridge Institute of Language Research.

Marshall, C. R. (2004). The morpho-phonological interface in children with Specific Language Impairment. Unpublished doctoral thesis, University of London.

Marshall, C. R. (2006). The morpho-phonological interface in Specific Language Impairment. Language Acquisition, 13, 373375.

Marshall, C. R., \& van der Lely, H. (2006). A challenge to current models of past tense inflection: The impact of phonotactics. Cognition, 100, 302-320.

Marshall, C. R., \& van der Lely, H. K. J. (2007). Derivational morphology in children with Grammatical-Specific Language Impairment. Clinical Linguistics, 21, 71-91.

McClelland, J. L., \& Patterson, K. (2002). Rules or connections in past tense inflection: What does the evidence rule out? Trends in Cognitive Sciences, 6, 465-472.

Norbury, C. F., Bishop, D., \& Briscoe, J. (2001). Production of English finite verb morphology: A comparison of SLI and mild-moderate hearing impairment. Fournal of Speech, Language, and Hearing Research, 44, 165-178.

Oetting, J., \& Horohov, J. (1997). Past-tense marking by children with and without specific language impairment. Fournal of Speech, Language, and Hearing Research, 40, 62-74.

Pinker, S. (1984). Language learnability and language development. Cambridge, MA: Harvard University Press.

Rapin, I., \& Allen, D. (1983). Developmental language disorders: Nosolgic considerations. In U. Kirk (Ed.), Neuropsychology of language, reading and spelling (pp. 155-184). New York: Academic Press.

Raven, J. C. (1998). Raven's Progressive Matrices. Oxford: Oxford Psychologists Press.

Rice, M., \& Wexler, K. (1996). Towards tense as a clinical marker of specific language impairment in English-speaking children. Fournal of Speech and Hearing Research, 39, 1239-1257.

Rice, M., Wexler, K., \& Cleave, P. (1995). Specific language impairment as a period of extended optional infinitive. Fournal of Speech and Hearing Research, 38, 850-863. 
Rice, M., Wexler, K., \& Hershberger, S. (1998). Tense over time: The longitudinal course of tense acquisition in children with specific language impairment. Fournal of Speech, Language and Hearing Research, 41, 1412-1431.

Rice, M., Wexler, K., \& Redmond, S. M. (1999). Grammaticality judgments of an extended optional infinitive grammar: Evidence from English-speaking children with specific language impairment. Fournal of Speech, Language and Hearing Research, 42, 943-961.

Rosen, S. (2003). Auditory processing in dyslexia and specific language impairment: Is there a deficit? What is its nature? Does it explain anything? fournal of Phonetics, 31, 509-527.

Shriberg, L. D., Tomblin, J. B., \& McSweeny, J. L. (1999). Prevalence of speech delay in 6-year-old children and comorbidity with language impairment. Fournal of Speech, Language, and Hearing Research, 42, 1461-1481.

SLI Consortium (2002). A genomewide scan identifies two novel loci involved in specific language impairment. American fournal of Human Genetics, 70, 384-398.

Song, J. Y., \& Demuth, K. (2005). Effects of syllable structure complexity on the early production of word-final grammatical morphemes. Paper presented at the $10^{\text {th }}$ International Congress for the Study of Child Language, Berlin, July.

Stemberger, J. P., \& Bernhardt, B. H. (1997). Phonological constraints and morphological development. In E. Hughes, M. Hughes \& A. Greenhill (Eds.), Proceedings of the $24^{\text {th }}$ Annual Boston University Conference on Language Development (pp. 602-614). Somerville, MA: Cascadilla Press.

Tallal, P., \& Piercy, M. (1973a). Defects of non-verbal auditory perception in children with developmental aphasia. Nature, 241, 468-469.

Tallal, P., \& Piercy, M. (1973b). Developmental aphasia: Impaired rate of non-verbal processing as a function of sensory modality. Neuropsychologia, 11, 389-398.

Ullman, M., \& Gopnik, M. (1999). Inflectional morphology in a family with inherited SLI. Applied Psycholinguistics, 20, $51-$ 117.

van der Lely, H. K. J. (1996). Test of Active and Passive Sentences (TAPS). Available from the author.

van der Lely, H. K. J. (1997a). Narrative discourse in Grammatical Specific Language Impaired children: A modular language deficit? fournal of Child Language, 24, 221-256.

van der Lely, H. K. J. (1997b). Language and cognitive development in a Grammatical SLI boy: Modularity and Innateness. Fournal of Neurolinguistics, 10, 75-107. van der Lely, H. K. J. (1997c). Advanced Test of Pronominal Reference $(A-S T O P)$. Available from the author.

van der Lely, H. K. J. (1998). SLI in children: Movement, economy and deficits in the computational-syntactic system. Language Acquisition, 7, 161-192.

van der Lely, H. K. J. (2000). Verb Agreement and Tense Test (VATT). Available from the author.

van der Lely, H. K. J. (2003). Do heterogeneous SLI deficits need heterogeneous theories? SLI subgroups, G-SLI and the RDDR hypothesis. In Y. Levy, \& J. Schaeffer (Eds.), Towards a definition of specific language impairment (pp. 109-134). Mahwah, NJ: Lawrence Erlbaum Associates.

van der Lely, H K. J. (2005). Domain-specific cognitive systems: Insight from grammatical specific language impairment. Trends in Cognitive Sciences, 9, 53-59.

van der Lely, H. K. J. \& Battell, J. (2003). Wh-movement in children with grammatical SLI: A test of the RDDR Hypothesis. Language, 79, 153-181.

van der Lely, H. K. J., \& Christian, V. (2000). Lexical word formation in grammatical SLI children: A grammar-specific or input-processing deficit? Cognition, 75, 33-63.

van der Lely, H. K. J., Rosen, S., \& Adlard, A. (2004). Grammatical language impairment and the specificity of cognitive domains: Relations between auditory and language abilities. Cognition, 94, 167-183.

van der Lely, H. K. J., Rosen, S. \& McClelland, A. (1998). Evidence for a grammar specific deficit in children. Current Biology, 8, 1253-1258.

van der Lely, H. K. J., \& Stollwerck, L. (1996). A grammatical specific language impairment in children: An autosomal dominant inheritance? Brain and Language, 52, 484-504.

van der Lely, H. K. J., \& Stollwerck, L. (1997). Binding theory and specifically language impaired children. Cognition, 62, 245290.

van der Lely, H. K. J., \& Ullman, M. (2001). Past tense morphology in specifically language impaired children and normally developing children. Language and Cognitive Processes, $16,177-217$.

Wexler, K. (1998). Very early parameter setting and the unique checking constraint: A new explanation of the optional infinitive stage. Lingua, 106, 23-79. 
Appendix 1. Details of the G-SLI participants (z-scores calculated on the basis of the published norms).

\begin{tabular}{|c|c|c|c|c|c|c|c|}
\hline Code & Age & $\begin{array}{c}\text { TROG } \\
\text { (z-score) }\end{array}$ & $\begin{array}{c}\text { BPVS } \\
\text { (z-score) }\end{array}$ & $\begin{array}{c}\text { NVIQ } \\
\text { (z-score) }\end{array}$ & $\begin{array}{c}\text { VATT } \\
(\% \text { correct })\end{array}$ & $\begin{array}{c}\text { TAPS } \\
(\% \text { correct })\end{array}$ & $\begin{array}{l}\text { A-STOP } \\
\text { (\% correct) }\end{array}$ \\
\hline $\mathrm{BD}$ & $9 ; 09$ & -2.27 & -2.10 & $-.07^{\mathrm{R}+\mathrm{B}}$ & 12.50 & 39.58 & 54.17 \\
\hline SA & $10 ; 00$ & -1.73 & -1.53 & $-.53^{\mathrm{R}}$ & 67.50 & 79.17 & 72.92 \\
\hline QC & $10 ; 02$ & -1.73 & -1.93 & $-.93^{\mathrm{R}}$ & 10.00 & 64.58 & 43.75 \\
\hline HD & $10 ; 05$ & -2.40 & -1.53 & $-.90^{\mathrm{BM}}$ & $\mathrm{n} / \mathrm{a}$ & 60.42 & $\mathrm{n} / \mathrm{a}$ \\
\hline CT & $11 ; 05$ & -2.07 & -2.60 & $-.40^{\mathrm{R}}$ & 2.50 & 62.50 & 47.92 \\
\hline GS & $11 ; 08$ & -2.27 & .80 & $-.85^{\mathrm{BM}}$ & 10.00 & 72.22 & 58.33 \\
\hline SL & $11 ; 10$ & -2.47 & -1.90 & $.03^{\mathrm{R}}$ & 42.50 & 30.56 & 70.83 \\
\hline $\mathrm{LJ}$ & $12 ; 00$ & -1.20 & -1.20 & $.53^{\mathrm{R}+\mathrm{B}}$ & 72.50 & 54.17 & 80.56 \\
\hline OD & $12 ; 02$ & -2.07 & -2.50 & $-.23^{\mathrm{R}}$ & 12.50 & 36.11 & 68.75 \\
\hline WS & $13 ; 00$ & -1.20 & -.13 & $-.20^{\mathrm{R}}$ & 80.00 & $\mathrm{n} / \mathrm{a}$ & $\mathrm{n} / \mathrm{a}$ \\
\hline $\mathrm{RP}$ & $13 ; 06$ & -1.20 & -1.33 & $-1.00^{\mathrm{R}}$ & 20.00 & 58.33 & 79.17 \\
\hline SM & $13 ; 09$ & -1.30 & -1.60 & $1.15^{\mathrm{R}+\mathrm{B}}$ & 12.50 & $\mathrm{n} / \mathrm{a}$ & $\mathrm{n} / \mathrm{a}$ \\
\hline GD & $14 ; 03$ & -.70 & -2.20 & $-.71^{\mathrm{R}+\mathrm{B}}$ & 27.50 & 62.50 & $\mathrm{n} / \mathrm{a}$ \\
\hline $\mathrm{CM}$ & $16 ; 03$ & -.70 & -2.00 & $-.07^{\mathrm{R}+\mathrm{B}}$ & 60.00 & $\mathrm{n} / \mathrm{a}$ & $\mathrm{n} / \mathrm{a}$ \\
\hline Mean & $12 ; 03$ & -1.67 & -1.53 & -.30 & 36.96 & 55.67 & 62.15 \\
\hline (SD) & $(1 ; 11)$ & (.61) & $(.76)$ & $(.54)$ & $(25.32)$ & (14.66) & (13.06) \\
\hline
\end{tabular}

$\mathrm{TROG}=$ Test for Reception of Grammar (Bishop, 1983); BPVS = British Picture Vocabulary Scales (Dunn et al., 1997); NVIQ = nonverbal IQ tests, ${ }^{\mathrm{R}}=$ Raven's Progressive Matrices (Raven, 1998); ${ }^{\mathrm{BM}}=$ Composite score of the Block Design and Matrices subtests from the British Ability Scales (Elliott, 1996) ${ }^{\mathrm{R}+\mathrm{B}}=$ Composite score of Ravens and the Block Design subtest from the British Ability Scales; VATT $=$ Verb Agreement and Tense Test (van der Lely, 2000); TAPS = Test of Active and Passive Sentences (van der Lely, 1996); A-STOP $=$ Advanced Syntactic Test of Pronominal Reference (van der Lely, 1997).

\begin{tabular}{|c|c|c|c|c|c|}
\hline \multirow[b]{2}{*}{ Condition } & \multirow[b]{2}{*}{ Verbs } & \multicolumn{2}{|c|}{ COBUILD } & \multicolumn{2}{|c|}{ CHILDES } \\
\hline & & $\begin{array}{c}\text { Lemma } \\
\text { Frequency }\end{array}$ & $\begin{array}{l}\text { Past tense } \\
\text { frequency }\end{array}$ & $\begin{array}{l}\text { Lemma } \\
\text { Frequency }\end{array}$ & $\begin{array}{l}\text { Past tense } \\
\text { frequency }\end{array}$ \\
\hline \multirow[t]{9}{*}{ V-D } & poured ${ }^{\star}$ & 6.31 & 4.90 & 5.45 & 3.18 \\
\hline & weighed & 5.58 & 3.69 & 3.81 & 1.95 \\
\hline & paid & 7.69 & 6.13 & 5.37 & 3.71 \\
\hline & sewed & 4.48 & 1.79 & 4.19 & 2.71 \\
\hline & purred $^{\star}$ & 3.56 & 1.79 & 1.79 & .00 \\
\hline & showed & 8.04 & 5.91 & 7.81 & 4.99 \\
\hline & sighed & 5.18 & 4.51 & 1.79 & .00 \\
\hline & lied & 5.20 & 3.18 & 6.05 & 2.20 \\
\hline & Mean (SD) & $5.76(1.53)$ & 3.99 (1.68) & $4.53(2.08)$ & $2.34(1.73)$ \\
\hline \multirow[t]{17}{*}{ VC-D } & hugged & 4.55 & 3.00 & 4.66 & 3.14 \\
\hline & hummed & 4.88 & 2.48 & 4.74 & 3.56 \\
\hline & robbed & 4.55 & 3.09 & 2.71 & 1.61 \\
\hline & fished & 5.66 & 3.47 & 6.16 & 3.71 \\
\hline & buzzed & 4.33 & 2.40 & 4.99 & 3.22 \\
\hline & touched & 6.67 & 4.98 & 4.57 & 3.14 \\
\hline & judged & 5.65 & 4.03 & 4.62 & 1.61 \\
\hline & washed & 6.62 & 4.66 & 5.15 & 2.48 \\
\hline & yelled & 5.67 & 3.74 & 4.66 & 3.14 \\
\hline & wrapped & 5.59 & 4.48 & 4.74 & 3.56 \\
\hline & tossed & 5.00 & 3.74 & 2.71 & 1.61 \\
\hline & kissed & 6.08 & 4.74 & 6.16 & 3.71 \\
\hline & killed & 7.21 & 5.81 & 4.99 & 3.22 \\
\hline & packed & 5.26 & 4.26 & 4.57 & 3.14 \\
\hline & coughed & 5.00 & 2.83 & 4.62 & 1.61 \\
\hline & hopped & 4.29 & 2.64 & 5.15 & 2.48 \\
\hline & Mean (SD) & $5.44(0.90)$ & $3.76(1.00)$ & $4.70(.92)$ & $2.81(.80)$ \\
\hline \multirow[t]{9}{*}{ VCC-D } & pinched & 4.26 & 2.94 & 4.14 & 2.83 \\
\hline & banged $\star \star$ & 5.11 & 3.14 & 5.55 & 3.04 \\
\hline & winked & 4.20 & 2.83 & 2.40 & .00 \\
\hline & solved & 5.83 & 4.25 & 2.40 & 1.95 \\
\hline & milked & 4.60 & 1.79 & 7.23 & .69 \\
\hline & punched & 4.30 & 3.04 & 4.81 & 2.08 \\
\hline & munched & 3.99 & 1.79 & 1.39 & .00 \\
\hline & danced & 6.61 & 3.97 & 6.08 & 2.83 \\
\hline & Mean (SD) & $4.86(.93)$ & $2.97(.88)$ & $4.25(2.04)$ & $1.68(1.27)$ \\
\hline
\end{tabular}

^These two verbs do not end in a cluster for speakers whose accent is non-rhotic, as all our participants' are.

$\star \star T h e / g /$ is pronounced in these participants' dialect. 


\section{Appendix 3}

Stimuli

V-D

Last year Kipper sewed a dress. Every year I sew a dress. Last year I.........

Yesterday Kipper sighed a bit. Everyday I sigh a bit. Yesterday I . . . . . . . .

Yesterday Kipper lied a bit. Everyday I lie a bit. Yesterday I . . . . . . . .

Last week Kipper paid a bill. Every week I pay a bill. Last week I. . . . . . . .

Last night Kipper poured a drink. Every night I pour a drink. Last night I. . . . . ...

Yesterday Kipper weighed a parcel. Everyday I weigh a parcel. Yesterday I.........

Yesterday Kipper showed off to his friends. Everyday I show off to my friends. Yesterday I ........

Yesterday Kipper purred at a cat. Everyday I purr at a cat. Yesterday I . . . . . ...

\section{VC-D}

Last week Kipper killed a rat. Every week I kill a rat. Last week I . . . . . . . .

Yesterday Kipper hugged a friend. Everyday I hug a friend. Yesterday I . . . . . . .

Yesterday Kipper kissed a girl. Everyday I kiss a girl. Yesterday I..........

Yesterday Kipper touched a flower. Everyday I touch a flower. Yesterday I.........

Yesterday Kipper packed a lunchbox. Everyday I pack a lunchbox. Yesterday I. . . . .....

Yesterday Kipper tossed a pancake. Everyday I toss a pancake. Yesterday I. .

Yesterday Kipper wrapped a present. Everyday I wrap a present. Yesterday I. . . . . . ...

Last week Kipper robbed a post office. Every week I rob a post office. Last week I.........

Yesterday Kipper buzzed at a bee. Everyday I buzz at a bee. Yesterday I . . . . . ...

Yesterday Kipper fished in the river. Everyday I fish in the river. Yesterday I.........

Last year Kipper judged a competition. Every year I judge a competition. Last year I . . . . . . .

Last winter Kipper coughed a lot. Every winter I cough a lot. Last winter I . . . . . ...

Yesterday Kipper yelled at his mum. Every day I yell at my mum. Yesterday I... . . . ..

Last night Kipper hummed a tune. Every night I hum a tune. Last night I . . . . . . .

Last night Kipper hopped around the bed. Every night I hop around the bed. Last night I........ Yesterday Kipper washed a blanket. Everyday I wash a blanket. Yesterday I... ........

\section{VCC-D}

Yesterday Kipper winked at his mum. Everyday I wink at my mum. Yesterday I . . . .....

Last month Kipper solved a crime. Every month I solve a crime. Last month I . . . . . . . .

Last week Kipper punched a burglar. Every week I punch a burglar. Last week I. . . . . . ...

Last night Kipper danced a jig. Every night I dance a jig. Last night I . . . . . . . .

Yesterday Kipper pinched a hamster. Everyday I pinch a hamster. Yesterday I..........

Yesterday Kipper munched a carrot. Every day I munch a carrot. Yesterday I.........

Yesterday Kipper milked a cow. Every day I milk a cow. Yesterday I . . . . . . . .

Last night Kipper banged on the door. Every night I bang on the door. Last night I........ 